\title{
Emerging therapies for patients with symptoms of opioid-induced bowel dysfunction
}

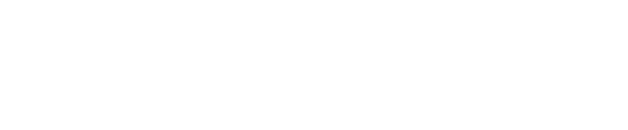

\section{Wojciech Leppert}

Chair and Department of Palliative Medicine, Poznan University of Medical Sciences, Poznan, Poland
Correspondence: Wojciech Leppert Chair and Department of Palliative Medicine, Poznan University of Medical Sciences, Osiedle Rusa 25A, 6I-245

Poznan, Poland

Tel +48 6I 8738303

Fax +48 6I 8738303

Email wojciechleppert@wp.pl
Abstract: Opioid-induced bowel dysfunction (OIBD) comprises gastrointestinal (GI) symptoms, including dry mouth, nausea, vomiting, gastric stasis, bloating, abdominal pain, and opioid-induced constipation, which significantly impair patients' quality of life and may lead to undertreatment of pain. Traditional laxatives are often prescribed for OIBD symptoms, although they display limited efficacy and exert adverse effects. Other strategies include prokinetics and change of opioids or their administration route. However, these approaches do not address underlying causes of OIBD associated with opioid effects on mostly peripheral opioid receptors located in the GI tract. Targeted management of OIBD comprises purely peripherally acting opioid receptor antagonists and a combination of opioid receptor agonist and antagonist. Methylnaltrexone induces laxation in $50 \%-60 \%$ of patients with advanced diseases and OIBD who do not respond to traditional oral laxatives without inducing opioid withdrawal symptoms with similar response $(45 \%-50 \%)$ after an oral administration of naloxegol. A combination of prolonged-release oxycodone with prolonged-release naloxone (OXN) in one tablet (a ratio of $2: 1$ ) provides analgesia with limited negative effect on the bowel function, as oxycodone displays high oral bioavailability and naloxone demonstrates local antagonist effect on opioid receptors in the GI tract and is totally inactivated in the liver. OXN in daily doses of up to $80 \mathrm{mg} / 40 \mathrm{mg}$ provides equally effective analgesia with improved bowel function compared to oxycodone administered alone in patients with chronic non-malignant and cancer-related pain. OIBD is a common complication of long-term opioid therapy and may lead to quality of life deterioration and undertreatment of pain. Thus, a complex assessment and management that addresses underlying causes and patomechanisms of OIBD is recommended. Newer strategies comprise methylnaltrexone or OXN administration in the management of OIBD, and OXN may be also considered as a preventive measure of OIBD development in patients who require opioid administration.

Keywords: methylnaltrexone, naloxegol, opioid-induced constipation, oxycodone/naloxone, quality of life, opioid-induced bowel dysfunction

\section{Introduction}

Pain is a worldwide problem, and all efforts should be made to allow its effective management in each suffering patient. ${ }^{1}$ It is of paramount importance to assess pain precisely in its physical but also psychological, social, and spiritual dimensions, especially in patients suffering from chronic pain syndromes. ${ }^{2}$ Chronic pain management rules are based on the analgesic ladder established in 1986 by the World Health Organization (WHO). ${ }^{3}$ In most patients, pain is successfully relieved through the use of pharmacotherapy including opioids alone, or in combination with adjuvant analgesics in accordance with the WHO analgesic ladder. ${ }^{4-7}$ Pain management guidelines for cancer patients have been recently updated by the EAPC (European Association for Palliative Care) and ESMO (European Society for Medical Oncology). ${ }^{8,9}$ 
Morphine, along with oxycodone and hydromorphone administered orally, are recommended as the first choice opioids at the third step of the WHO analgesic ladder, which also comprises additional opioids (transdermal formulations of fentanyl and buprenorphine, methadone and tapentadol) for the treatment of cancer patients with moderate-to-severe pain intensity. Currently, instead of weak opioids (opioids for mild-to-moderate pain), it is possible to use low doses of strong opioids (opioids for moderate-to-severe pain): morphine up to $30 \mathrm{mg}$, oxycodone up to $20 \mathrm{mg}$, and hydromorphone up to $4 \mathrm{mg}$ per day, administered by the oral route on the second step of the WHO analgesic ladder. ${ }^{10}$

Opioids are often successfully used for pain management, but they may also induce numerous and potentially serious adverse effects (AE). Although tolerance develops only for some opioid AE, such as sedation, there may be little or no tolerance development to opioid-induced gastrointestinal (GI) AE. Therefore, patients should be closely monitored by the staff to avoid or decrease the intensity of opioid-induced $\mathrm{AE}$ that may significantly affect patients' quality of life (QoL) and lead to non-compliance with opioid regimens resulting in undertreatment of chronic pain. ${ }^{11}$ One common opioid adverse effect is a group of symptoms associated with the GI tract, the so called opioid-induced bowel dysfunction (OIBD). ${ }^{12}$

\section{Epidemiology of OIBD}

OIBD is a frequent phenomenon. Among 40 cancer patients with different primary tumor locations admitted to a palliative medicine inpatient unit, $84 \%$ suffered from dry mouth, $71 \%$ complained of early satiety, $58 \%$ reported constipation, $56 \%$ anorexia, $50 \%$ bloating, $48 \%$ nausea, $42 \%$ abdominal pain, and 34\% vomiting. ${ }^{13}$ In an Internet study conducted in Europe and in the US, of 322 patients taking oral opioids for chronic cancer-related and noncancer pain, and laxatives, $45 \%$ reported less than three bowel movements (BM) per week. Constipation was reported by $81 \%$ of patients and straining during defecation by $58 \%$ of the patients surveyed. The most bothersome symptoms were, in order of rank: constipation, straining, fatigue, small and hard stools, and insomnia. A third of patients had missed, decreased, or stopped using opioids in order to make it easier to have a BM. ${ }^{14}$ In a study conducted in Spain among 317 outpatients taking different opioids for chronic cancer-related and noncancer pain, $94.6 \%$ of patients reported at least one symptom of OIBD, with constipation reported most frequently $(91.6 \%)$. Nearly half of the patients reported three or more symptoms with severity equal or above 4 on the numerical rating scale (11- point scale from 0 to 10 ). No significant differences were found in the prevalence of symptoms between patients treated with different opioids (morphine, oxycodone, fentanyl, or buprenorphine). A decrease related to moderate-to-severe GI symptom severity in the well-being of patients was detected. ${ }^{15}$

In patients with non-malignant pain taking a median morphine dose of $127.5 \mathrm{mg}$, the most common symptoms comprised chronic abdominal pain (58.2\% of patients), constipation (46.9\%), gastro-esophageal reflux (33\%), nausea (27\%), and vomiting (10\%). ${ }^{16}$ In another multicenter, observational study, among 2,324 patients surveyed, morphine (89.6\%) and transdermal fentanyl (74.1\%) more often induced OIBD than oxycodone and transdermal buprenorphine (59.3\% each). Age over 70 years, cancer-related pain, and transdermal fentanyl were the risk factors for the development of OIBD symptoms. ${ }^{17}$ In another study conducted among 4,040 patients, similar constipation intensity was found in those treated with controlled-release (CR) morphine, CR oxycodone, and transdermal fentanyl with no difference between cancer and noncancer patients. ${ }^{18}$ In France, among 520 cancer patients with pain treated with opioids, $61.7 \%$ showed the degree of constipation that is problematic for the patient; $85.7 \%$ of patients were considered constipated according to physicians' assessment despite laxatives used by $84.7 \%$ of patients. QoL was significantly reduced in constipated versus (vs) non-constipated patients $(P<0.0001)$. Hospitalization, pain, and changes in laxative and opioid treatment are all consequences of OIBD development. ${ }^{19}$

\section{Pathophysiology of OIBD}

OIBD symptoms reflect a complex impact of opioids on the GI tract (Table 1). The most typical and usually most burdensome symptoms of OIBD are called opioid-induced constipation (OIC). However, OIBD reflects the impact of opioids on the whole GI tract, which comprises such symptoms as: dry mouth; gastro-esophageal reflux-related symptoms (heartburn); nausea; vomiting; chronic abdominal pain; bloating; constipation-related symptoms, such as straining, hard stools, painful, infrequent, and incomplete BM; and diarrhea-related symptoms, such as urgency, loose BM, and frequent BM. ${ }^{12}$

\section{Opioid impact on gut motility}

The patomechanism of OIBD is associated mainly with the peripheral opioid effect on $\mu$-opioid receptors in the gut wall, with probably less central effects. ${ }^{20}$ The $\mu$-opioid receptors are present in neurons of myenteric and submucosal plexus and immune cells in the lamina propria. ${ }^{21}$ Opioid receptors (predominantly $\mu$, but also $\kappa$ and $\delta$ ) are located in the 
Table I Pharmacological mechanisms and clinical symptoms of opioid-induced bowel dysfunction

\begin{tabular}{|c|c|}
\hline Pharmacological mechanisms & Clinical symptoms \\
\hline Decreased saliva production & Xerostomia \\
\hline Dysmotility of the lower esophageal sphincter & Gastro-esophageal reflux (or, rarely, dysphagia) \\
\hline Decreased gastric secretion, emptying and motility & Delayed absorption of medication, upper abdominal discomfort \\
\hline Disturbed fluid secretion and absorption & Constipation \\
\hline $\begin{array}{l}\text { Abnormal bowel motility, increased resting contractile tone in the } \\
\text { small and large intestinal circular muscles, and sphincter dysfunction }\end{array}$ & $\begin{array}{l}\text { Straining, incomplete bowel evacuation, bloating, abdominal } \\
\text { distension, constipation }\end{array}$ \\
\hline Increased amplitudes of non-propulsive segmental bowel contractions & $\begin{array}{l}\text { Spasm, abdominal cramps and pain, stasis of luminal contents, } \\
\text { and hard dry stool }\end{array}$ \\
\hline Constriction of sphincter of Oddi & Biliary colic, epigastric discomfort, and pain \\
\hline $\begin{array}{l}\text { Increased anal sphincter tone and impaired reflex relaxation during rectal } \\
\text { distension }\end{array}$ & Evacuation disorders \\
\hline Diminished intestinal, pancreatic, and biliary secretion & Hard, dry stools \\
\hline $\begin{array}{l}\text { Abnormal bowel motility, increased fermentation and meteorism, } \\
\text { opioid-induced hyperalgesia }\end{array}$ & Chronic visceral pain \\
\hline Central effects of opioids & Nausea and vomiting, anorexia \\
\hline
\end{tabular}

Notes: Adapted from: Springer International Publishing AG; Drugs; Opioid-induced bowel dysfunction: pathophysiology and management; 72(I4); 20I2; I847-I865; Brock C, Olesen SS, Olesen AE, Frøkjaer JB, Andresen T, Drewes AM; Copyright (C) Springer International Publishing AG 20I2; with kind permission of Springer Science+Business Media. ${ }^{12}$

myenteric plexus and in the submucosal plexus of the gut wall. The myenteric plexus lies between the longitudinal and circular layers and extends the length of the intestine, and it is mainly responsible for the control of motor activity of the gut. The submucosal plexus controls secretion and absorption; $\mu$-opioid receptors are activated in the wall of the stomach, and small and large intestine by endogenous (enkephalins, endorphins, and dynorphins) and exogenous (eg, morphine, oxycodone, and methadone) opioids, and modify GI function. Activation of $\mu$-opioid receptors inhibits excitatory and inhibitory neural pathways within the enteric nervous system, which coordinates motility. Inhibition of excitatory neural pathways decreases peristaltic contractions. In turn, the blockade of inhibitory neural pathways increases GI muscle activity and elevates resting muscle tone, spasm, and non-propulsive motility patterns. These mechanisms induce delayed gastric emptying and slow intestinal transit. ${ }^{22}$

Several neurotransmitters are involved in the regulation process of gut motility. Acetylcholine release activates the cholinergic excitatory motoneurons in the longitudinal smooth muscles. Nitric oxide and vasoactive intestinal peptide control the inhibition of the non-cholinergic inhibitory neurons in the circular smooth muscles. The coordination of the contractile and propulsive gut motility is determined by the balance between acetylcholine and nitrous oxide plus vasoactive intestinal peptide release. Opioids inhibit the release of these neurotransmitters and disrupt the coordination of gut motility. ${ }^{12}$
In the esophagus, opioids induce non-peristaltic contractions with an incomplete relaxation of the lower esophageal sphincter. This may manifest as dysphagia. In the small and large intestine, opioids increase resting contractile tone in the circular muscle and decrease tonic inhibition of the muscle tone, which together leads to an increased tone in the circular muscle layer. Increased tone is accompanied by enhanced rhythmic contractions and occasional, high-amplitude, nonpropulsive phasic contractions and associated changes in smooth muscle electrical activity. All these abnormalities result in an increased segmental contraction along with decreased propulsive forward peristalsis. Clinically, these changes manifest as constipation, gut spasm, and abdominal cramps. A consequence of this peristaltic disruption is stasis of luminal contents, which leads to an increased passive absorption of fluids, dryer and harder stools. ${ }^{12}$

\section{Opioid impact on gut secretion}

Activation of opioid receptors in the submucosa inhibits water and electrolyte secretion into the gut lumen, and increases fluid absorption from the intestine and blood flow in the gut wall. ${ }^{23}$ Opioids increase activity in the sympathetic nervous system and decrease the secretion. Endocrine cells located in the epithelium play a role in regulating motor activity and secretion in the gut. Studies conducted in mice indicate that peripheral $\mu$-opioid receptors inhibit the transit independently of central $\mu$-receptors. ${ }^{24}$ Opioids increase ileocecal and anal sphincter tones and impair defecation reflex through reduced sensitivity to distension, and increased internal anal sphincter 
tone. ${ }^{25}$ Morphine causes sphincter contraction and decreases emptying of pancreatic juice and bile, ${ }^{26}$ which may delay digestion. ${ }^{26}$ The anal sphincter dysfunction is an important factor in the sensation of anal blockage. ${ }^{27,28}$

\section{Peripheral and central effects of opioids on the gut}

Central mechanisms of opioid effects on GI tract were demonstrated in an experimental study in which intracerebroventricular administration of morphine in rats, inhibited GI propulsion. ${ }^{29}$ This effect was reversed by intracerebroventricular administration of naloxone ${ }^{30}$ and vagotomy. ${ }^{31}$ Intrathecal administration of morphine reduced gastroduodenal motility, and morphine administered intramuscularly, yielded additional effects. Thus, both central and peripheral opioid action may play a role in opioid GI effects. ${ }^{32}$ The indirect evidence of both central and peripheral components of opioid effects on bowel function may be observed in the $50 \%-60 \%$ response rate to the treatment of OIBD with methylnaltrexone (MNTX), which displays purely peripheral $\mu$-opioid receptor antagonist effects. ${ }^{33,34}$ However, in humans, it seems that the peripheral opioid effects dominate GI transit. OIBD is the consequence of reduced GI motility, increased absorption of fluids from the gut, and decreased epithelial secretion. The stool remains in the gut lumen for a longer time; therefore, more fluid is reabsorbed and the stool becomes hard and dry. These effects are also associated with opioids' inhibition of secretomotor neurons in the epithelium of the gut. ${ }^{35}$

\section{Clinical assessment of patients with OIBD}

The complex assessment of patients with symptoms of OIBD is necessary for the application of effective treatment. Several subjective scales were developed for that purpose, eg,

Table 2 The Bowel Function Index (BFI)

\begin{tabular}{|c|c|}
\hline Item & Intensity \\
\hline Ease of defecation during the & \begin{tabular}{|l|l|l|l|l|l|l|l|l|l|l|}
$\underline{0}$ & $\underline{1}$ & $\underline{2}$ & $\underline{3}$ & $\underline{4}$ & $\underline{5}$ & $\underline{6}$ & $\underline{7}$ & $\underline{8}$ & $\underline{9}$ & $\underline{10}$ \\
\end{tabular} \\
\hline \multicolumn{2}{|l|}{ last 7 days according to patient } \\
\hline \multicolumn{2}{|l|}{ assessment } \\
\hline Feeling of incomplete bowel & \begin{tabular}{|l|l|l|l|l|l|l|l|l|l|l|}
$\underline{0}$ & 1 & $\underline{2}$ & $\underline{3}$ & $\underline{4}$ & $\underline{5}$ & $\underline{6}$ & $\underline{7}$ & $\underline{8}$ & $\underline{9}$ & 10 \\
\end{tabular} \\
\hline \multicolumn{2}{|l|}{ evacuation during the last 7 days } \\
\hline \multicolumn{2}{|l|}{ according to patient assessment } \\
\hline Personal judgment of patient & \begin{tabular}{|l|l|l|l|l|l|l|l|l|l|l|}
$\underline{0}$ & $\underline{1}$ & $\underline{2}$ & $\underline{3}$ & $\underline{4}$ & $\underline{5}$ & $\underline{6}$ & $\underline{7}$ & $\underline{8}$ & $\underline{9}$ & $\underline{10}$ \\
\end{tabular} \\
\hline \multicolumn{2}{|l|}{ regarding constipation during } \\
\hline \multicolumn{2}{|l|}{ the last 7 days } \\
\hline $\begin{array}{l}\text { Note: Adapted from: Validation of t } \\
\text { meaningful changes in opioid-induced }\end{array}$ & $\begin{array}{l}\text { Function Index to detect clinically } \\
\text { n; Rentz AM, Yu R, Müller-Lissne }\end{array}$ \\
\hline $\begin{array}{l}\text { S, Leyendecker P; Journal of Medical } \\
\text { Healthcare; adapted by permission of }\end{array}$ & $\begin{array}{l}\text { 2009; Copyright @ } 2009 \text { Inform } \\
\text { er Informa Healthcare. }{ }^{36}\end{array}$ \\
\hline
\end{tabular}

Stool

Table 3 Patient assessment of constipation symptom questionnaire (PAC-SYM)

\begin{tabular}{|c|c|}
\hline Domain & Item \\
\hline Abdominal & $\begin{array}{l}\text { - Discomfort in your stomach } \\
\text { - Pain in your stomach } \\
\text { - Bloating in your stomach } \\
\text { - Stomach cramps }\end{array}$ \\
\hline Rectal & $\begin{array}{l}\text { - Painful bowel movements } \\
\text { - Rectal burning during or after bowel movement } \\
\text { Rectal bleeding or tearing during or after bowel } \\
\text { movement }\end{array}$ \\
\hline Stool & $\begin{array}{l}\text { - Incomplete bowel movements, like you did not } \\
\text { " } \text { - Binish" } \\
\text { - Bowel movements that were too hard } \\
\text { - Straining or squeezing to try to pass a bowel } \\
\text { - movement } \\
\text { - Feeling like you had to pass a bowel movement } \\
\text { but could not ("false alarm") }\end{array}$ \\
\hline
\end{tabular}

Notes: PAC-SYM comprises three domains: abdominal, rectal, and stool symptom mechanisms. Responses are scored as 0 , absence of symptoms; I, mild symptoms; 2 , moderate symptoms; 3 , severe symptoms; and 4, very severe symptoms. Adapted with permission from: Slappendel R, Simpson K, Dubois D, Keininger DL; European Journal of Pain; John Wiley and Sons; Validation of the PAC-SYM questionnaire for opioid-induced constipation in patients with chronic low back pain; 2006;10(3):209_ 217; Copyright (C 1999-2015 John Wiley \& Sons, Inc. All Rights Reserved. ${ }^{40}$ 
Table 4 Patient assessment of constipation quality of life questionnaire (PAC-QOL)

\begin{tabular}{|c|c|}
\hline Domain & Item \\
\hline Worries and concerns & $\begin{array}{l}\text { - Been increasingly bothered by not being able to have a bowel movement } \\
\text { - Felt stressed by your condition } \\
\text { - Been worried about not being able to have a bowel movement } \\
\text { - Been worried about not knowing when you are going to be able to have a bowel movement } \\
\text { - Been upset by your condition } \\
\text { - Been worried that your condition will get worse } \\
\text { - Felt less self-confident because of your condition } \\
\text { - Felt that your body was not working properly } \\
\text { - Felt irritable because of your condition } \\
\text { - Felt in control of your situation } \\
\text { - Felt obsessed by your condition }\end{array}$ \\
\hline Physical discomfort & $\begin{array}{l}\text { - Felt bloated to the point of bursting } \\
\text { - Felt heavy because of your constipation } \\
\text { - Felt any physical discomfort } \\
\text { - Felt the need to have bowel movement but not been able to }\end{array}$ \\
\hline Psychological discomfort & $\begin{array}{l}\text { - Been embarrassed to be with other people } \\
\text { - Been embarrassed about staying in bathroom for so long when you were away from home } \\
\text { - Been embarrassed about staying in bathroom so often when you were away from home } \\
\text { - Been eating less and less because of not being able to have bowel movements } \\
\text { - Been worried about not being able to choose what you eat } \\
\text { - Had to be careful what you eat } \\
\text { - Been worried about having to change your daily routine } \\
\text { - Had a decreased appetite }\end{array}$ \\
\hline Satisfaction & $\begin{array}{l}\text { - Satisfied with how often you have a bowel movement } \\
\text { - Satisfied with the regularity of your bowel movements } \\
\text { - Satisfied with the time it takes for food to pass through the intestines } \\
\text { - Satisfied with your treatment }\end{array}$ \\
\hline
\end{tabular}

Notes: PAC-QOL comprises four domains and 28 items, all evaluated by the patient on a 5 -point ( 0 to 4$)$ Likert scale ranging from 0 , not at all or none of the time to 4 , extremely or all of the time. Adapted with permission from: Development and validation of the Patient Assessment of Constipation Quality of Life questionnaire; Marquis P, De La Loge C, Dubois D, McDermott A, Chassany O; Scandinavian Journal of Gastroenterology. 2005; Copyright @ 2005 Informa Healthcare; 40(5):540-55I; reprinted by permission of the publisher Informa Healthcare. ${ }^{41}$

validation study has confirmed that PAC-QOL is internally consistent, reproducible, valid, and responsive to improvements over time. ${ }^{41}$ The objective assessment comprises the Bristol Stool Chart - a simple and easy-to-use method of objective assessment detecting stool frequency and stool consistency. However, only a moderate correlation between stool form and whole-gut or colonic transit time can be demonstrated. ${ }^{42}$

Clinical evaluation is composed of a detailed history that should take into account GI symptoms with comprehensive assessment of other physical problems along with psychological and spiritual concerns. Careful physical examination includes palpation of abdomen, auscultation of peristalsis, and rectal examination. Specifically, acute abdominal diseases should be excluded such as bowel obstruction or gut perforation. Investigations comprise plain radiography, transit time studies, manometry, and anorectal dysfunction tests. However, apart from plain radiography, these investigations are rarely used in patients with advanced diseases. ${ }^{43}$

\section{Management of OIBD}

Several drug groups may be used for the management of OIBD. However, most of these do not address the underlying cause of this condition. The currently available interventions for patients with OIBD symptoms are presented in Table 5. ${ }^{44}$

\section{Non-targeted treatment of OIBD Prokinetic agents}

Metoclopramide is commonly prescribed for patients with symptoms of gastroparesis. It works through both peripheral (in the upper GI tract) and central mechanisms by inducing antidopaminergic effects. The typical dose of metoclopramide is usually $10 \mathrm{mg}$ three times a day. The most common AE comprise restlessness, drowsiness, and fatigue. Metoclopramide may induce extra-pyramidal effects, especially in younger patients and in children, and therefore should be avoided in these patients. Nonetheless, it is recommended to be used for a short period of time, ie, a few days in other patients. Metoclopramide is an inhibitor 
Table 5 Pharmacological management of opioid-induced bowel dysfunction

\begin{tabular}{|c|c|c|}
\hline Treatment & Pharmacological mechanisms & Drugs \\
\hline Prokinetics, & Improve motility of the upper GI tract, increase & Metoclopramide, domperidone \\
\hline \multirow[t]{3}{*}{ D2 receptor antagonists } & lower esophageal sphincter tone & \\
\hline & Improve motility of the whole Gl tract due to & Itopride \\
\hline & inhibition of acetylcholinesterase & \\
\hline Prokinetics, & Improve GI motility & Tegaserod, cisapride - both drugs \\
\hline \multirow[t]{2}{*}{ 5- $\mathrm{HT}_{4}$ receptor agonist } & & withdrawn due to cardiotoxicity \\
\hline & & Prucalopride \\
\hline Prokinetics, & Stimulation of intestinal fluid secretion inducing softer & Lubiprostone \\
\hline chloride channels agonists & stools, increased colonic transit and stool frequency & \\
\hline Prokinetics & Stimulation of $\mathrm{Gl}$ secretion and transit - increase & Linaclotide \\
\hline activating guanylate cyclase $\mathrm{C}$ & stool frequency, stool weight, and ease stool passage & \\
\hline Laxatives, & Activation of myenteric plexus in the colon - & Sennosides, bisacodyl \\
\hline stimulants & promotion of propulsive motility & \\
\hline Laxatives - osmotic agents: & Metabolism to short-chain fatty acids by gut bacteria & Lactulose, sorbitol \\
\hline \multicolumn{3}{|l|}{ saccharines (sugar alcohols) } \\
\hline Laxatives - osmotic agents: & Decrease Gl transit time & Polyethylene glycol 3350 \\
\hline \multicolumn{3}{|l|}{ macrogol } \\
\hline Laxatives - osmotic agents: & Secretion of fluid into intestinal lumen & Magnesium hydroxide, sodium \\
\hline magnesium and sodium salts & & biphosphate \\
\hline Laxatives - detergents & Increase Gl secretion and decrease surface tension & Docusate \\
\hline Opioid receptor agonists + & Targeting peripheral $\mu$-opioid receptors, without & Combined prolonged-release \\
\hline \multirow[t]{2}{*}{ opioid receptor antagonists } & affecting analgesia due to naloxone inactivation in the & oxycodone/prolonged-release \\
\hline & liver & naloxone tablets \\
\hline Purely peripheral acting & Targeting of peripheral of $\mu$-opioid receptor, without & Methylnaltrexone, naloxegol \\
\hline$\mu$-opioid receptor & affecting analgesia due its inability to cross the & Alvimopan - approved in the US \\
\hline \multirow[t]{4}{*}{ antagonists } & blood-brain barrier & only to accelerate the time to upper \\
\hline & & and lower Gl recovery after partial \\
\hline & & large or small bowel resection \\
\hline & & surgery with primary anastomosis \\
\hline
\end{tabular}

Notes: Adapted from Rauck RL. Treatment of opioid-induced constipation: focus on the peripheral $\mu$-opioid receptor antagonist methylnaltrexone. Drugs. 20।3; 73(12): 1297-1306. ${ }^{44}$

Abbreviation: $\mathrm{Gl}$, gastrointestinal.

of CYP2D6 enzyme. ${ }^{45}$ Concurrent use of antidepressants such as tricyclics, selective serotonin reuptake inhibitors, and antidepressants acting as serotonin-noradrenalin reuptake inhibitors (venlafaxine, or duloxetine) may enhance AE of metoclopramide. ${ }^{46}$ Domperidone may be an alternative drug, which in contrast to metoclopramide, does not cross the blood-brain barrier and displays less risk of extra-pyramidal effects. ${ }^{47}$ Cisapride, a $5-\mathrm{HT}_{4}$ receptor agonist, works in the whole GI tract, but it is not recommended due to the high risk of cardiotoxicity. ${ }^{48}$

Itopride is a peripheral antidopaminergic agent that also increases acetylcholine levels due to the inhibition of acetylcholinesterase, and the prokinetic effect observed in the whole GI tract. It does not activate $5-\mathrm{HT}_{4}$ or $5-\mathrm{HT}_{3}$ receptors. Itopride is metabolized through a mono-oxidase system, and there is little risk of significant pharmacokinetic interactions with other medications. Itopride does not permeate the blood-brain barrier and poses no risk of extra-pyramidal effects. The recommended dose is normally $50 \mathrm{mg}$ three times a day. ${ }^{49}$
Newer prokinetics, such as prucalopride, lubiprostone, and linaclotide have recently been introduced. Prucalopride is a selective $5-\mathrm{HT}_{4}$ receptor agonist which stimulates propulsive gut motility in vitro and in vivo. Prucalopride in the daily doses of 2-4 mg accelerates the whole gut, gastric, small bowel, and colonic transit in patients with chronic constipation. ${ }^{50}$ The recommended dose is usually $2 \mathrm{mg}$ once daily. However, prucalopride was introduced for the treatment of chronic constipation, predominantly in women. ${ }^{51}$ The most common AE comprise headache $(25 \%-30 \%$ of treated patients), nausea $(12 \%-24 \%)$, abdominal cramps (16\%-23\%), and diarrhea (12\%-19\%). ${ }^{52}$ A phase- 2 controlled study conducted during 4 weeks in 196 patients with noncancer pain and OIC found an increase in the number of complete spontaneous BM in patients treated with prucalopride at a daily dose of 2-4 mg compared to placebo, but the difference did not reach statistical significance. ${ }^{53}$ Both itopride and prucalopride do not interfere with cardiac functioning.

Lubiprostone activates type-2 chloride channels and increases intestinal fluid secretion, thereby facilitating 
intestinal transit and increasing the passage of stool ${ }^{54}$ It was demonstrated to be effective in patients with OIC suffering from non-malignant pain. Lubiprostone is registered by the US Food and Drug Administration (FDA) for the management of OIBD in patients with chronic non-malignant pain based on the results of three phase-3 trials (NCT00595946, NCT01298219, and NCT00597428) that demonstrated superiority of the drug over placebo. The most common AE comprised nausea (11\% of treated patients), diarrhea $(8 \%)$, and abdominal pain (4\%). However, in contrast to morphine, lubiprostone may be ineffective in patients treated with methadone. ${ }^{55}$

Linaclotide is an agent that regulates chloride secretion on the intestinal epithelial cells through activation of guanylate cyclase C. Linaclotide stimulates the GI secretion and transit, and also modulates visceral sensitivity. It increases stool frequency, stool weight, and improves the ease of stool passage. The main AE of linaclotide is diarrhea. ${ }^{56}$ Linaclotide may be potentially considered for the management of OIBD, although this drug was only used in patients with chronic constipation and irritable bowel syndrome. ${ }^{57}$

\section{Laxatives}

Numerous laxatives are prescribed for the prevention and treatment of OIBD, particularly for constipation-related symptoms. The most commonly used group of laxatives for OIBD comprise osmotic agents and stimulants. Nonetheless, they possess limited efficacy and display their own AE..$^{58}$ Moreover, treatment with laxatives should be limited to a short period of time. Patients with chronic non-malignant and cancer-related pain usually have to take laxatives for the long term, as tolerance to the constipating effect of opioids develops to little extent or not at all. OIBD is often unsuccessfully managed due to not only the lack of efficacy and AE of traditional laxatives, but also due to the lack of appropriate clinical evaluation and knowledge on OIBD management and expertise of the medical staff. ${ }^{59}$

\section{Change of opioid route of administration and opioid rotation (switch)}

Another approach is a change from oral to parenteral or to transdermal route of opioid administration. However, all opioids display OIBD including transdermal formulations. ${ }^{60}$ From the point of view of physicochemical properties, it may be beneficial to switch from hydrophilic opioids such as morphine, oxycodone, or hydromorphone to lipophilic opioids such as fentanyl, buprenorphine, or methadone due to more involvement of GI receptors with hydrophilic formulations and less with lipophilic formulations. ${ }^{61}$ However, only few studies demonstrated improvement in constipation, predominantly after the switch from oral to transdermal opioids. ${ }^{62,63}$

\section{Targeted treatment of OIBD}

Newer strategies for the management of OIBD include administration of purely peripherally acting opioid receptor antagonists, predominantly MNTX and a combination of prolonged-release (PR) oxycodone with PR naloxone (OXN) in one tablet. MNTX is administered in the form of subcutaneous injections when treatment of OIBD with traditional oral laxatives has failed to provide effective bowel movements. ${ }^{64} \mathrm{OXN}$ renders analgesia with limited negative effect of oxycodone on bowel function. ${ }^{65}$

\section{Combining PR oxycodone with PR naloxone Pharmacodynamics and pharmacokinetics}

Oxycodone is an opioid agonist that predominantly binds to $\mu$ and $\kappa$ opioid receptors. ${ }^{65}$ Naloxone is an opioid antagonist that acts at $\mu, \kappa$, and $\delta$ opioid receptors. Naloxone displaces opioid agonists from the receptors due to higher affinity, and when administered by the oral route it improves bowel function in patients with OIBD. ${ }^{66}$ The chemical structure of oxycodone and naloxone is shown on Figure 1. OXN tablets contain PR oxycodone and PR naloxone in different strengths: $5 \mathrm{mg} / 2.5 \mathrm{mg}, 10 \mathrm{mg} / 5 \mathrm{mg}, 20 \mathrm{mg} / 10 \mathrm{mg}$, and $40 \mathrm{mg} / 20 \mathrm{mg}$. The $2: 1$ ratio of oxycodone/naloxone was deemed optimal in a phase- 2 study conducted in patients with severe chronic pain as effective analgesia and improvement in bowel function; ${ }^{67}$ the observed AE were

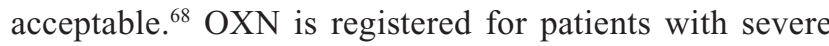
pain that may only be successfully treated with opioid analgesics. ${ }^{69,70}$

OXN analgesia provided by oxycodone is not reversed by naloxone; opioid withdrawal is not observed (Figure 2). An important difference between the administration of immediate-release (IR) and PR formulations of naloxone is that IR naloxone may attenuate analgesia or induce opioid
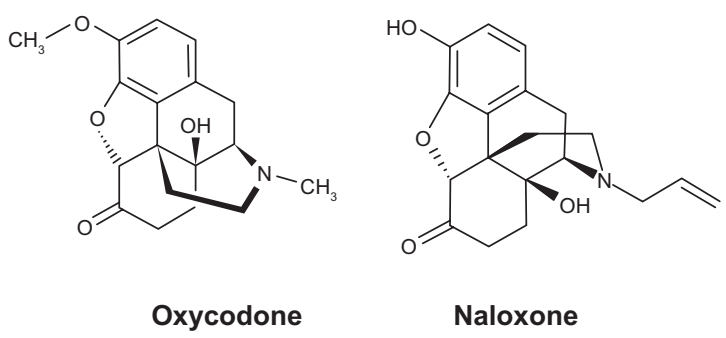

Figure I Chemical structures of oxycodone and naloxone. 


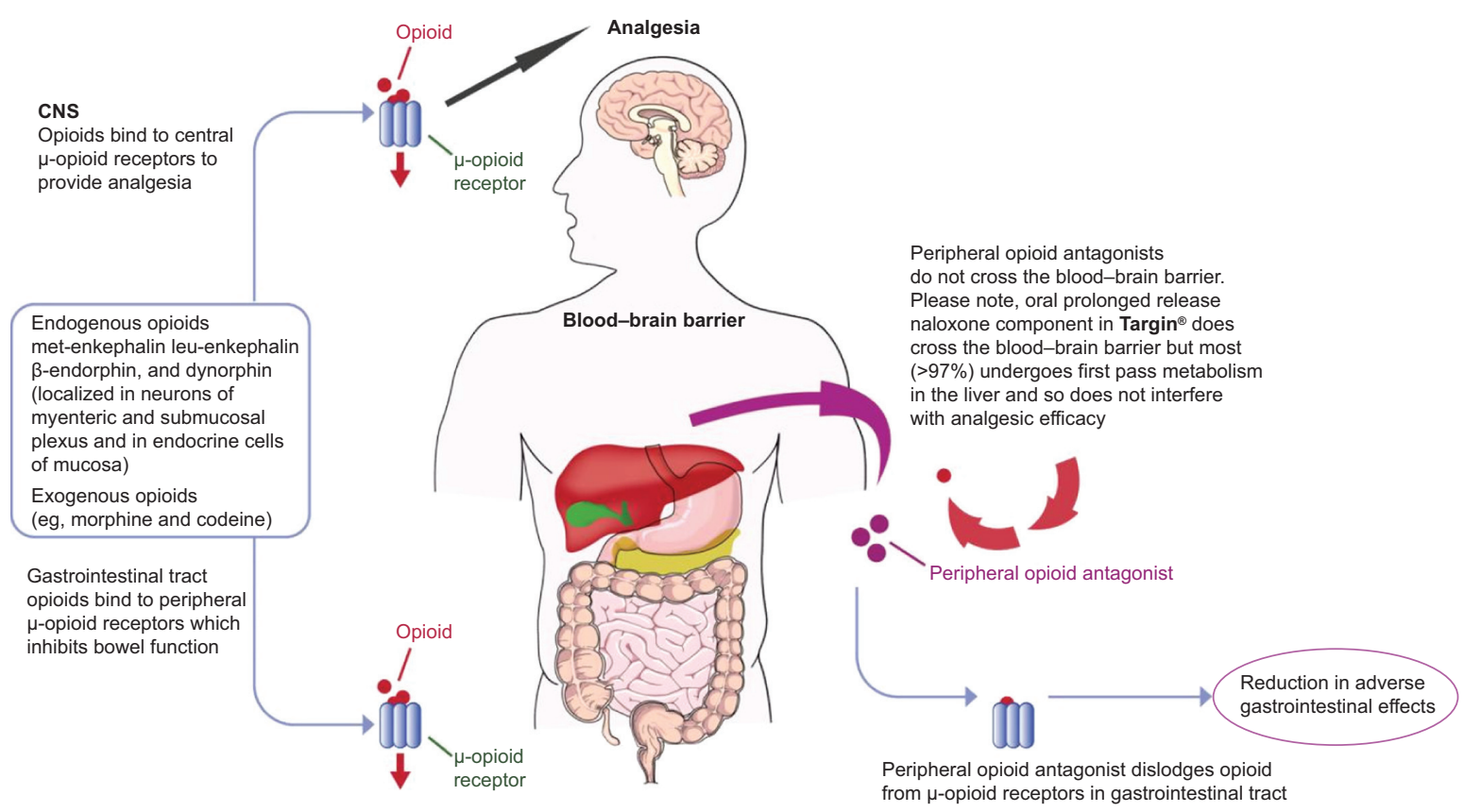

Figure 2 Mechanisms of action of opioid agonist/antagonist combinations to counteract opioid-induced bowel dysfunction development. Abbreviation: CNS, central nervous system.

withdrawal. ${ }^{71} \mathrm{PR}$ naloxone prevents the saturation of hepatic enzymes responsible for naloxone metabolism, and reduces the risk of passing naloxone on to systemic circulation and opioid antagonism in the central nervous system. OXN is contraindicated in patients with bowel obstruction, acute abdominal conditions, diarrhea, allergy to the drug, and hepatic failure. OXN should not be administered before and 12-24 hours after the surgery. As no data exist for the administration of $\mathrm{OXN}$ in children and patients under 18 years of age, the drug should not be administered in these patient populations. ${ }^{72,73}$

Oxycodone displays high oral bioavailability (60\%-87\%) and is metabolized primarily in the liver and in the intestine wall, predominantly through CYP3A to noroxycodone, and to less extent through CYP2D6 to oxymorphone. As oxycodone is metabolized through CYP3A and CYP2D6, drugs inhibiting these enzymes, especially CYP3A, should be avoided due to the risk of an increase in oxycodone plasma levels that may lead to toxicity. ${ }^{70}$ The highest risk is associated with concurrent administration of CYP2D6 and CYP3A4 inhibitors. ${ }^{74}$ The risk of drug interactions in the case of naloxone is lower due to the type of metabolism (glucuronidation) without P-450 system involvement. ${ }^{65}$

Oxycodone and its metabolites are excreted with urine and with feces..$^{70}$ The volume of distribution of oxycodone equals 2-3 L/kg. The maximum plasma concentration is reached within 25 minutes after intravenous injection, 1.3 hours after IR administration, and 2.6 hours after the administration of a CR formulation. The $\mathrm{T}_{1 / 2}$ (half-life) is approximately 2-3 hours after intravenous administration, 3 hours after administration with an IR, and approximately 5 hours after treatment with PR oxycodone tablets. Oxycodone predominantly binds to albumin $(45 \%){ }^{65}$

Naloxone exhibits low oral bioavailability $(<3 \%)$ and extensive first-pass metabolism in the liver, with the formation of naloxone-3-glucuronide (NAL-3-G). Another naloxone metabolic pathway is $\mathrm{N}$-dealkylation and the reduction of the 6-keto group to 6-alpha-naloxol and 6-beta-naloxol, although only the latter has been detected in humans. ${ }^{75}$ NAL$3-\mathrm{G}$ is measured in plasma instead of the parent compound, which is undetectable after oral administration. Naloxone and its metabolites are excreted with urine. The effect of orally administered naloxone depends on normal liver function; thus, any hepatic impairment should be carefully considered. In patients suffering from liver failure, PR oxycodone/PR naloxone administration is not recommended. ${ }^{76}$

Highly fatty meals may insignificantly increase oxycodone bioavailability. Food consumption does not affect NAL-3-G levels, and OXN may be administered in fasting condition or with food. OXN was not studied in patients during pregnancy and delivery. However, oxycodone and naloxone penetrate to placenta, and their long-term administration in pregnant women may evoke opioid withdrawal syndrome in neonates. Oxycodone permeates to the milk; thus, OXN should not be administered in lactating women. ${ }^{72}$ 


\section{Dosing guidelines}

The starting OXN doses in opioid-naïve patients are normally in the range of $5 \mathrm{mg} / 2.5 \mathrm{mg}-10 \mathrm{mg} / 5 \mathrm{mg}$ administered twice daily (every 12 hours). In patients not responding to opioids, for mild-to-moderate pain (tramadol, codeine, dihydrocodeine, or hydrocodone), the initial dose usually recommended equals $10 \mathrm{mg} / 5 \mathrm{mg}$ or $20 \mathrm{mg} / 10 \mathrm{mg}$ twice daily. The dose may be titrated to achieve satisfactory analgesia and tolerable AE. The recommended maximal daily dose of OXN is $40 \mathrm{mg} / 20 \mathrm{mg}$ administered twice daily. However, higher daily doses of up to $120 \mathrm{mg} / 60 \mathrm{mg}$ were safely administered in clinical studies. ${ }^{77}$ When OXN doses exceed the recommended dose range, a rotation to oxycodone administered alone, or other opioids for moderate-to-severe pain intensity should be instituted.

When rotating from other opioids for moderate-to-severe pain to $\mathrm{OXN}$, the starting dose is established individually, depending on the amount of the opioid administered, analgesia, AE, and complex clinical evaluation. Patients treated with OXN should have access to IR formulations of opioids for breakthrough pain management. In the case of IR oxycodone, a single dose usually equals approximately a sixth of the daily oxycodone dose used in OXN. However, when using IR opioids for breakthrough pain management, especially rapid onset fentanyl formulations, the treatment should always be started with the lowest dose and then be titrated to achieve good analgesia and acceptable toxicity. ${ }^{78} \mathrm{OXN}$ should be administered with caution in patients with renal impairment; in patients with renal failure, a switch to fentanyl or buprenorphine should be considered. ${ }^{6}$ As OXN is contained in PR formulations, the whole tablets should be swallowed without crushing, gnawing, or chewing. ${ }^{65}$

\section{Adverse effects}

AE of OXN and PR oxycodone are similar. The frequency of diarrhea is higher in patients treated with OXN compared to those treated with PR oxycodone alone (5.2\% vs $2.6 \%)$, ${ }^{79}$ with less frequent nausea ( $6.3 \%$ vs $10.5 \%)$, vomiting ( $1.3 \%$ vs $4.3 \%)$, abdominal pain (1.3\% vs $4.3 \%)$ and dyspepsia ( $0.6 \%$ vs $2.5 \%)$, compared to PR oxycodone administered alone. ${ }^{80}$ These effects are associated with naloxone antagonist effect on opioid receptors in the GI tract, ${ }^{81}$ and prokinetic properties. ${ }^{82}$ In another study, most GI AE were more frequent in patients treated with OXN (23.8\%) compared with PR oxycodone (16.3\%): abdominal pain $(7.7 \%$ vs $1.5 \%)$, constipation $(0.8 \%$ vs $1.5 \%)$, diarrhea ( $4.6 \%$ vs $3.0 \%)$, nausea $(10.0 \%$ vs $6.7 \%)$, and vomiting $(3.1 \%$ vs $0.7 \%)$, respectively. ${ }^{83}$
Long-term treatment with OXN over a period of up to 52 weeks in patients with chronic pain who completed 12 weeks of treatment in two phase- 3 studies, ${ }^{79,80}$ was safe. ${ }^{84}$ A total of $6.3 \%$ of treated patients discontinued therapy with OXN due to AE. The most commonly reported AE were constipation $(9.2 \%)$, nausea (7.7\%), back pain and depression (6.3\% each), and diarrhea (3.2\%). Withdrawal symptoms were experienced by $0.53 \%$ of all treated patients. ${ }^{84}$ Similar incidences of all AE from OXN (61.0\%) and PR oxycodone (57.3\%), GI AE (20.9\% and 21.7\%, respectively; diarrhea, $5.1 \%$ and $3.7 \%$, respectively), and discontinuation rate due to $\mathrm{AE}(4.8 \%$ and $6.4 \%$, respectively) were found in an analysis of two controlled studies ${ }^{80,83}$ conducted in patients with chronic non-malignant pain. ${ }^{85}$ No increase in the incidence of opioid withdrawal syndrome during treatment with $\mathrm{OXN}$ in daily doses up to $120 \mathrm{mg} / 60 \mathrm{mg}$ compared to oxycodone was found.$^{83}$ Long-term study of cancer (24 weeks) and noncancer patients (1 year) confirmed good analgesic efficacy and safety without withdrawal symptoms during tretment with OXN. ${ }^{86,87}$

Mercadante et al ${ }^{88}$ in a case report depicted a cancer patient with severe pain who required high OXN daily doses $(240 \mathrm{mg} / 120 \mathrm{mg})$, which turned out to be ineffective. A switch to PR oxycodone administered alone at a daily dose of $240 \mathrm{mg}$ provided satisfactory analgesia. This case report suggests that at higher doses $(240 \mathrm{mg} / 120 \mathrm{mg}$ daily), OXN provides inferior analgesia compared to PR oxycodone administered alone at a respective daily dose $(240 \mathrm{mg}){ }^{88}$

Kang et al ${ }^{89}$ depicted a female patient diagnosed with gastric cancer with peritoneal seeding, extensive thrombosis in the portal vein, and abdominal pain. PR oxycodone at a dose of $10 \mathrm{mg}$ administered twice daily provided satisfactory analgesia but caused OIC not amenable to laxative therapy. For this reason, the patient was rotated to $\mathrm{OXN}$ at a dose of $10 \mathrm{mg} / 5 \mathrm{mg}$ administered twice daily. After taking OXN, the patient experienced severe pain and symptoms such as chills, diarrhea, general weakness, and sweating suggesting opioid withdrawal. The patient returned to the former treatment with PR oxycodone $10 \mathrm{mg}$ administered twice daily, and her pain was again effectively relieved, and other symptoms disappeared. This result suggests development of a collateral circulation due to portal vein thrombosis, and naloxone directly reaching the central nervous system and evoking withdrawal symptoms. ${ }^{89}$ Numerous other studies have demonstrated clinical effectiveness of $\mathrm{OXN}$ in patients with chronic nonmalignant pain, ${ }^{67,68,79,80,83,84,90-95}$ cancer-related pain, ${ }^{96-99}$ and postoperative pain. ${ }^{100,101}$ 


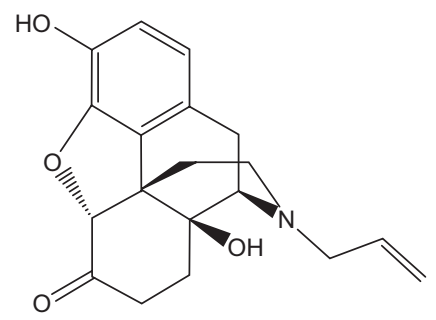

Naloxone

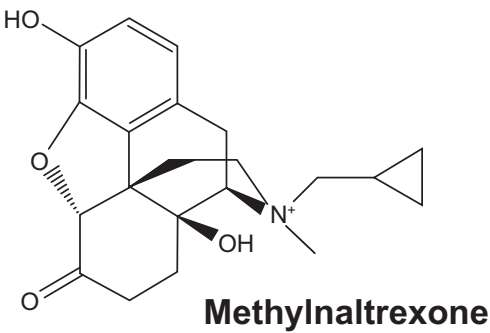

Methylnaltrexone

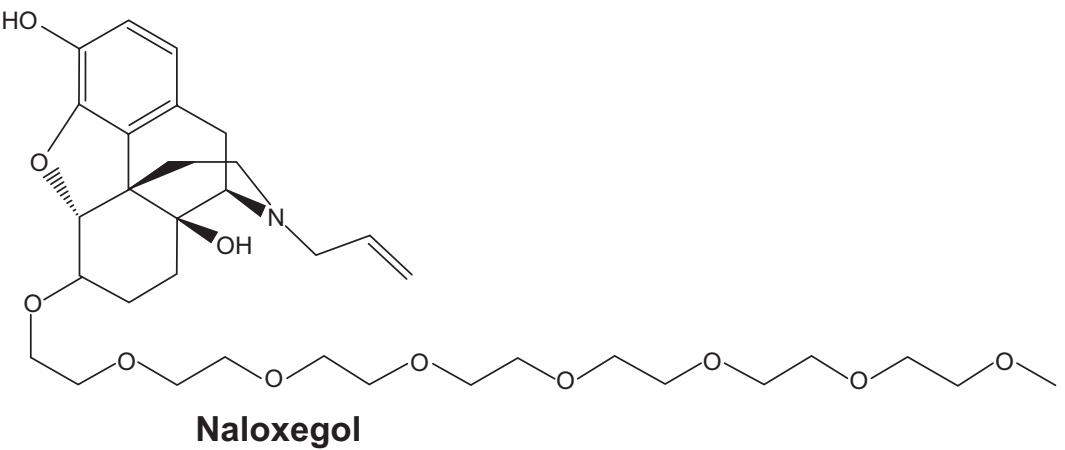

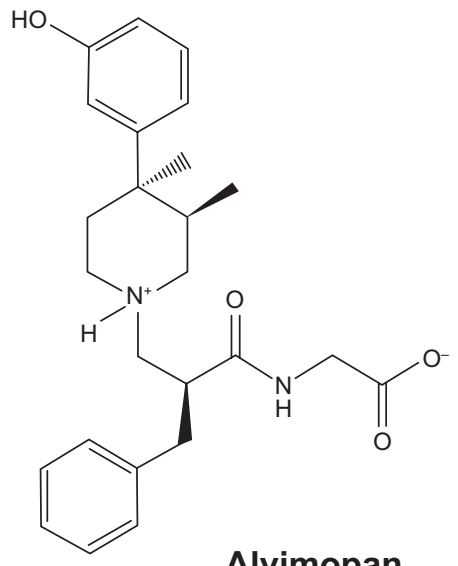

Alvimopan

Figure 3 Chemical structures of naloxone, methylnaltrexone, alvimopan, and naloxegol.

\section{Purely peripherally acting opioid receptor antagonists}

Treatment with opioid receptor antagonists that act purely peripherally may be used when traditional oral laxatives fail. ${ }^{102}$

Table 6 Mechanisms of action of purely peripherally acting $\mu$-opioid receptor antagonists (PAMORA)

\begin{tabular}{lll}
\hline Place of action & Opioid agonists' effects & Opioid antagonists' effects \\
\hline Central nervous system & Analgesia & No effect on analgesia \\
& Nausea & \\
& Vomiting & \\
& Sedation \\
& Decreased sensation of dyspnea & \\
Blood-brain barrier & Decreased gastric secretion, emptying and motility & \\
Enteric nervous system & Inhibition of propulsive intestinal contractions & PAMORA eg, methylnaltrexone, naloxegol \\
& Diminished intestinal, pancreatic and biliary secretion & Inhibition of opioid-induced \\
& Increased absorption of fluids and electrolytes & gastrointestinal adverse effects \\
Increased anal sphincter tone & \\
& Constipation & \\
\hline
\end{tabular}

Notes: Adapted from Springer International Publishing AG; Journal of Gastroenterology; Physiology, signaling, and pharmacology of opioid receptors and their ligands in the gastrointestinal tract: current concepts and future perspectives; 49(I); 20I4; 24-45; Sobczak M, Salaga M, Storr MA, Fichna J. Copyright @ The Authors 20I3; with kind permission of Springer Science+Business Media. ${ }^{104}$

\section{MNTX}

\section{Pharmacodynamics and pharmacokinetics}

MNTX is a quaternary methyl derivative of naltrexone, preferential, non-selective, peripheral $\mu$-opioid receptor antagonist. ${ }^{102}$ The addition of the methyl group to the 
nitrogen ring increases polarity and reduces lipophilicity of MNTX. As a consequence, MNTX does not cross the bloodbrain barrier and displays limited absorption from the gut. The chemical structures of naloxone, MNTX, naloxegol, and alvimopan are shown in Figure 3. When administered systemically (orally, subcutaneously, or intravenously), MNTX does not reverse opioid analgesia, which is the case for MNTX intrathecal administration. ${ }^{103}$ The principal mechanisms of action of MNTX are shown in Table $6 .{ }^{104}$

MNTX binds to $\mu$-opioid receptors and with less potency to $\kappa$-opioid receptors, and it does not bind to $\delta$-opioid receptors. The inhibition of propulsive motor activity in the gut by opioids is primarily mediated by the activation of local $\mu$-opioid receptors in the plexus myentericus of the GI tract. MNTX administration reverses the inhibiting effect of opioids on the gut during opioid therapy in patients and reduces fecal transit time in volunteers, the latter suggesting endogenous opioids' role in the regulation of gut motility. MNTX induces bowel movement in approximately $50 \%-60 \%$ treated patients within 4 hours of its administration. ${ }^{33,34}$ MNTX is registered for the treatment of OIC in patients with advanced illness who require palliative care. MNTX is used in the treatment of $\mathrm{OIC}$ in advanced diseases in adult patients when conventional oral laxatives are ineffective. ${ }^{64}$

MNTX is suggested to have little oral bioavailability. However, a study conducted in healthy volunteers demonstrated the efficacy of oral MNTX in the prevention of the delay in oro-cecal transit time after intravenous morphine administration. ${ }^{105}$ The levels of MNTX in plasma after ingestion of enteric-coated oral formulation (to prevent the absorption of the drug in the stomach and to release MNTX in the intestine) were substantially lower in comparison to those observed after administration of uncoated formulations, which may suggest a more efficient local action on opioid receptors in the gut of enteric-coated MNTX oral formulations. ${ }^{106} \mathrm{MNTX}$ is usually administered subcutaneously and is rapidly absorbed, with the peak plasma concentration attained within 30 minutes, and plasma $T_{1 / 2}$ is approximately 8 hours. ${ }^{107}$

After intravenous administration, a maximum plasma concentration is observed within 5 minutes, and plasma $\mathrm{T}_{1 / 2}$ equals approximately 2.5-2.9 hours. Approximately $11 \%-15 \%$ of MNTX binds to proteins. MNTX is a weak CYP2D6 inhibitor with no significant drug interactions. ${ }^{108}$ MNTX undergoes two major metabolic pathways in humans: 1) sulfation of the phenolic group to MNTX-3-sulphate (M2), and 2) reduction of the carbonyl group to two epimeric alcohols, methyl-6 $\alpha$-naltrexol (M4) and methyl-6 $\beta$-naltrexol
(M5). Neither naltrexone, nor its metabolite 6 $\beta$-naltrexol, was detected in human plasma after administration of MNTX, which confirmed that N-demethylation was not a metabolic pathway in humans. ${ }^{109}$ Approximately $10 \%$ of MNTX is metabolized through the glucuronidation process in the liver. As regards elimination, approximately $40 \%-50 \%$ is excreted mostly unchanged in urine, and approximately $20 \%$ through feces, with a total $70 \%$ recovery of the administered MNTX dose. ${ }^{110}$

Systematic reviews found MNTX to be effective in palliative care patients with OIC when conventional laxatives have failed. ${ }^{111,112}$ However, the safety of the product could not be clearly established; thus, large controlled trials are required. ${ }^{113}$ A more recent systematic review and meta-analysis of 14 controlled studies including 4,101 patients demonstrated superiority of mu-opioid receptor antagonists over placebo in the treatment of OIC. MNTX, naloxone, and alvimopan all were superior to placebo. $\mathrm{AE}$ (diarrhea and abdominal pain) were more common during these drugs' administration compared to placebo. Reversal of analgesia was not observed during active therapy. Lubiprostone was beneficial in two controlled studies, and prucalopride showed a tendency to elicit a better response in one study. ${ }^{114}$ However, MNTX failed to improve postoperative nausea and vomiting in women undergoing gynecological surgery. ${ }^{115}$

\section{Dosing recommendations}

The drug MNTX is available in ampules containing $12 \mathrm{mg}$ MNTX bromide in the volume of $0.6 \mathrm{~mL}$, and is applied via subcutaneous injections. The single MNTX dose equals $8 \mathrm{mg}$ in patients with body weight of $38-61 \mathrm{~kg}$, or $12 \mathrm{mg}$ if the body mass is $62-114 \mathrm{~kg} .{ }^{116}$ Patients falling outside of this range should receive a dose of $0.15 \mathrm{mg} / \mathrm{kg}$. A bowel movement within 4 hours after MNTX injection is observed in $50 \%-60 \%$ of patients (the median time to bowel movement after the drug administration is 30 minutes). If no therapeutic effect is observed, the injection may be repeated every other day. The efficacy of MNTX in patients who have already responded to the treatment reaches $57 \%-100 \%$ (2-7 doses); when the first, or the first two doses are ineffective, $35 \%$ patients respond to the second and $26 \%$ to the third dose, respectively. ${ }^{117}$ The European Medicines Agency (EMA) has approved subcutaneous administration of MNTX for the treatment of OIC in adults with advanced illness. ${ }^{118}$ The use of MNTX may eliminate the need for unpleasant rectal measures, which are poorly tolerated by patients. ${ }^{119}$ 
MNTX dosing is similar in younger and older patients. No dose adjustment is required in patients with mild-tomoderate renal impairment. However, in patients with renal failure (creatinine clearance $<30 \mathrm{~mL} / \mathrm{min}$ ), the MNTX dose should be reduced by half. No dose adjustment is required for patients with mild-to-moderate hepatic impairment. MNTX is not recommended for patients with end-stage renal impairment requiring dialysis, or for patients with severe liver impairment. ${ }^{120}$

\section{Adverse Effects}

MNTX may be used in palliative care patients with OIC not amenable to treatment with traditional oral laxatives, as demonstrated in clinical studies. ${ }^{33,34,116,117}$ However, long-term efficacy and safety of MNTX has not been clearly established. As MNTX does not cross the blood-brain barrier, the attenuation of analgesia or opioid withdrawal symptoms are not observed. ${ }^{34}$ The use of MNTX is contraindicated in patients with bowel obstruction, in acute abdominal conditions, diarrhea, and in the case of allergy to the drug. ${ }^{102}$

MNTX may induce several AE: abdominal pain $(28 \%$ of treated patients), flatulence (13\%), nausea (11\%), dizziness $(7 \%)$, and diarrhea (5\%), which usually have mild-tomoderate intensity and are associated with the defecation act. ${ }^{33}$ In an extension phase of this study, the most common AE comprised abdominal pain, typically of mild-to-moderate intensity (30.5\% of treated patients), malignant tumor progression (24.4\%), nausea (20.7\%), and vomiting (19.5\%). ${ }^{119}$ The most frequent $\mathrm{AE}$ observed in the analysis of the controlled study ${ }^{121}$ were as follows: abdominal pain $(19.3 \%$, $15.5 \%$, and $3.7 \%)$; diarrhea $(6.0 \%, 11.5 \%$, and $3.7 \%)$; and nausea $(8.7 \%, 11.5 \%$, and $6.2 \%)$ in patients receiving MNTX once daily, every other day, and placebo, respectively. ${ }^{122}$ MNTX may exacerbate vomiting induced by morphine after a single $8 \mathrm{mg}$ dose administration. ${ }^{123}$

In a few adult patients with OIC, advanced illness, and conditions that may induce local or diffuse reduction of structural integrity of the GI tract wall (eg, cancer, peptic ulcer, and Ogilvie's syndrome), MNTX caused GI perforation. GI perforations have been found in seven patients and involved varying regions of the GI tract, such as stomach, duodenum, and colon; in most cases, GI perforations appear after the first dose of MNTX. The concurrent medical conditions included two cases of duodenum peptic ulcer and single cases of amyotrophic lateral sclerosis, volvulus, bevacizumab use, metastatic colon cancer, and bowel obstruction. Interestingly, in a patient with amyotrophic lateral sclerosis diagnosis and constipation not responsive to traditional laxatives, MNTX was used without opioid administration. ${ }^{124}$
It is recommended that MNTX should be used with caution in patients with present or suspected lesions of the GI tract. Treatment with MNTX should be stopped if severe abdominal symptoms appear or intensify. If severe or persistent diarrhea occurs during the treatment, patients are advised to discontinue the MNTX therapy. ${ }^{120}$ In a retrospective chart review conducted on 200 patients who were prescribed MNTX (202 physicians' orders, 282 doses administered) in a comprehensive cancer center (inpatient and outpatient clinics), the prescription order was often not adherent to the label's indication. In 18\% of orders, MNTX was prescribed within 24 hours of the last bowel movement, 33\% of orders were for patients with non-advanced illness, and 25\% were for patients who had no OIC; $19 \%$ and $3 \%$ of orders were for patients who had no history of laxative and opioid use, respectively, and $5 \%$ of orders were for patients with documented bowel obstruction. ${ }^{125}$

Clinical studies have demonstrated the effectiveness of MNTX in the treatment of OIC not responding to traditional laxatives in patients with advanced diseases, ${ }^{33,34,116,117,121,122,126}$ non-malignant pain, ${ }^{127-129}$ and in other patient populations. ${ }^{130,131}$ However, MNTX was ineffective in shortening the duration of postoperative ileus following segmental colectomy. ${ }^{132}$

\section{Naloxegol}

Naloxegol (NKTR-118) is a polymer conjugate of the opioid antagonist naloxone administered once daily by the oral route. The polyethylene glycol moiety limits naloxegol capacity to cross the blood-brain barrier. ${ }^{133}$ In a phase-2, randomized, double-blind, placebo-controlled, dose-escalation study, the efficacy and safety of three dose levels of oral naloxegol in the treatment of OIC in patients with non-malignant or cancerrelated pain was evaluated. The dose of $25 \mathrm{mg}$ naloxegol was chosen to be further explored in phase-3 studies. ${ }^{134}$

Two phase-3, double-blind clinical studies (KODIAC-04 [NCT01309841] and KODIAC-05 [NCT01323790]) have been completed, and demonstrated significant increase in spontaneous BM compared to placebo for the $25 \mathrm{mg}$ naloxegol dose (in one study also for the $12.5 \mathrm{mg}$ dose), with arthralgia as the only $\mathrm{AE}$ more common than in the placebo group. In both studies (KODIAC-04, 652 participants; KODIAC-05, 700 participants), outpatients with noncancer pain and OIC were randomly assigned to receive a daily dose of 12.5 or $25 \mathrm{mg}$ of naloxegol or placebo, respectively. The primary endpoint was the 12-week response rate ( $\geq 3$ spontaneous BM per week, and an increase from baseline of $\geq 1$ spontaneous BM for $\geq 9$ of 12 weeks and for $\geq 3$ of the final 4 weeks) in the intention-to-treat population. The key secondary endpoints were the response rate in the subpopulation of patients with an inadequate response to laxatives before 
enrollment, time to first post-dose spontaneous BM, and mean number of days per week with one or more spontaneous BM.

Response rates were significantly higher with $25 \mathrm{mg}$ of naloxegol than with placebo (intention-to-treat population: KODIAC-04, 44.4\% vs $29.4 \%$, respectively [ $P=0.001]$; KODIAC-05, 39.7\% vs $29.3 \%$, respectively $[P=0.02]$; patients with an inadequate response to laxatives: KODIAC-04, 48.7\% vs $28.8 \%$, respectively [ $P=0.002$ ]; KODIAC- 05 , $46.8 \%$ vs $31.4 \%$, respectively $[P=0.01]$ ). In KODIAC-04, response rates were also higher in the group treated with $12.5 \mathrm{mg}$ of naloxegol than placebo (intention-to-treat population, $40.8 \%$ vs $29.4 \%$, respectively [ $P=0.02]$; in patients with an inadequate response to laxatives, rates for naloxegol vs placebo were $42.6 \%$ vs $28.8 \%$, respectively [ $P=0.03]$ ). A shorter time to the first post-dose spontaneous BM and a higher mean number of days per week with one or more spontaneous BM were observed with $25 \mathrm{mg}$ of naloxegol vs placebo in both studies $(P<0.001)$, and with $12.5 \mathrm{mg}$ of naloxegol in KODIAC-04 $(P<0.001)$. Pain scores and daily opioid dose were similar among the three groups. AE (primarily gastrointestinal) occurred most frequently in the groups treated with $25 \mathrm{mg}$ of naloxegol. Treatment with naloxegol, as compared with placebo, resulted in a significantly higher rate of treatment response, without reducing opioid-mediated analgesia. ${ }^{135,136}$ The most common AE of naloxegol are as follows: abdominal pain ( $21 \%$ of treated patients), diarrhea $(9 \%)$, nausea $(8 \%)$, flatulence $(6 \%)$, vomiting $(5 \%)$, headache (4\%), and hyperhidrosis (3\%).

Naloxegol was approved by the FDA for the treatment of OIC in adult patients with chronic non-malignant pain. Naloxegol is contraindicated in patients with known or suspected GI obstruction and those at increased risk of the potential for GI perforation, patients receiving strong CYP3A4 inhibitors (may increase exposure to naloxegol and precipitate opioid withdrawal symptoms) and patients with a known hypersensitivity reaction to naloxegol or any of its excipients [133 https://www.movantikhcp.com/ access 6th December 2014].

\section{Alvimopan}

Alvimopan is used to restore bowel function after surgery, for no more than 7 days (15 doses) and cannot be prescribed for outpatients. However, it is contraindicated for the treatment of OIBD in patients with advanced diseases due to the risk of myocardial infarction. ${ }^{137-140}$

\section{Conclusion and recommendations}

OIBD is a common complication in patients receiving longterm treatment with opioids. Nonetheless, significant progress has been made with targeted therapies for the management of patients with symptoms of OIBD, namely OXN, MNTX, and naloxegol. Any intervention should always be preceded with a meticulous assessment of the OIBD symptoms in the wider context of the underlying disease and comorbidities, and a thorough patient's assessment including non-medical problems should also be conducted.

The management of OIBD in the first instance may be based on traditional laxatives and prokinetics, especially newer agents such as prucalopride or lubiprostone. The second step may comprise a consideration of an opioid switch, especially from orally administered hydrophilic opioids, such as morphine, oxycodone, and hydromorphone, to more lipophilic transdermal opioids, such as buprenorphine, fentanyl, or drugs with non-opioid components, such as tapentadol or, in the case of mild-to-moderate pain, tramadol. When traditional laxatives and prokinetics are ineffective, the use of peripheral $\mu$-opioid receptor antagonists may be considered, with a preference of oral agents, if available. Furthermore, it needs to be noted that there is uncertainty in the MNTX role, because of the reports of GI perforation. The third step in treating OIBD may constitute rectal measures, including suppositories and enemas. OXN may be considered as a first-step approach in patients who already suffer from or are in high risk of OIBD development. However, limitations of OXN include the currently recommended daily dose range ( $80 \mathrm{mg} / 40 \mathrm{mg}$ ), and the fact that the patients must have normal hepatic function and portal circulation.

\section{Future perspectives}

Several purely peripherally acting opioid receptor antagonists, which are currently under investigation, include naldemedine (S-297995; NCT01965652), benvenopran (CB-5945) and axelopran (TD-1211). ${ }^{141}$ Further progress can be made by a more in-depth exploration of different mechanisms (eg, naloxonazine-sensitive vs naloxonazineinsensitive sites, peripheral or central mechanisms) of OIBD development by different opioids associated with their different impact on the GI tract, and finally the development of more effective, targeted therapies aimed at specific opioid receptor sites. ${ }^{142}$ Controlled clinical studies are needed to demonstrate long-term efficacy, safety, and costeffectiveness of new therapies, and to decrease the need for unpleasant and poorly accepted rectal interventions, thereby reducing OIBD costs and improving patients' compliance to opioid therapy. As a result of a more effective OIBD treatment, lower GI symptom burden and better effectiveness of pain management may be achieved, with a positive influence on patients' QoL. 


\section{Disclosure}

The author reports no conflicts of interest in this work.

\section{References}

1. Cousins MJ,Lynch ME. The Declaration Montreal: access to pain management is a fundamental human right. Pain. 2011;152(12):2673-2674.

2. Knudsen AK, Brunelli C, Klepstad P, et al. Which domains should be included in a cancer pain classification system? Analyses of longitudinal data. Pain. 2012;153(3):696-703.

3. World Health Organisation. Cancer pain relief and palliative care. Geneva: World Health Organisation; 1996.

4. Hanks GW, Conno F, Cherny N, et al; Expert Working Group of the Research Network of the European Association for Palliative Care. Morphine and alternative opioids in cancer pain: the EAPC recommendations. Br J Cancer. 2001;84(5):587-593.

5. Leppert W. Pain management in patients with cancer: focus on opioid analgesics. Curr Pain Headache Rep. 2011;15(4):271-279.

6. Lussier D, Huskey AG, Portenoy RK. Adjuvant analgesics in cancer pain management. Oncologist. 2004;9(5):571-591.

7. Eidelman A, White T, Swarm RA. Interventional therapies for cancer pain management: important adjuvants to systemic analgesics. $J$ Natl Compr Canc Netw. 2007;5(8):753-760.

8. Caraceni A. The EPCRC project to revise the European Association for Palliative Care (EAPC) guidelines on the use of opioids for cancer pain. Palliat Med. 2011;25(5):389-390.

9. Ripamonti CI, Bandieri E, Roila F; ESMO Guidelines Working Group. Management of cancer pain: ESMO Clinical Practice Guidelines. Ann Oncol. 2011;22(Suppl 6):vi69-vi77.

10. Caraceni A, Hanks G, Kaasa S, et al; European Palliative Care Research Collaborative (EPCRC), European Association for Palliative Care (EAPC). Use of opioid analgesics in the treatment of cancer pain: evidence-based recommendations from the EAPC. Lancet Oncol. 2012; 13(2):e58-e68.

11. Cherny N, Ripamonti C, Pereira J, et al; Expert Working Group of the European Association of Palliative Care Network. Strategies to manage the adverse effects of oral morphine: an evidence-based report. $J$ Clin Oncol. 2001;19(9):2542-2554.

12. Brock C, Olesen SS, Olesen AE, Frøkjaer JB, Andresen T, Drewes AM. Opioid-induced bowel dysfunction: pathophysiology and management. Drugs. 2012;72(14):1847-1865.

13. Komurcu S, Nelson KA, Walsh D, Ford RB, Rybicki LA. Gastrointestinal symptoms among inpatients with advanced cancer. Am J Hosp Palliat Care. 2002;19(5):351-355.

14. Bell TJ, Panchal SJ, Miaskowski C, Bolge SC, Milanova T, Williamson R. The prevalence, severity, and impact of opioid-induced bowel dysfunction: results of a US and European patient survey (PROBE 1). Pain Med. 2009;10(1):35-42.

15. Gálvez R, Provencio M, Cobo M, Pérez C, Pérez C, Canal J. [Observational and cross-sectional study of prevalence and severity of the opioid-induced bowel dysfunction]. Aten Primaria. 2014;46(1):32-39. Spanish [with English abstract]

16. Tuteja AK, Biskupiak J, Stoddard GJ, Lipman AG. Opioid-induced bowel disorders and narcotic bowel syndrome in patients with chronic non-cancer pain. Neurogastroenterol Motil. 2010;22(4):424-430.

17. Rosti G, Gatti A, Costantini A, Sabato AF, Zucco F. Opioid-related bowel dysfunction: prevalence and identification of predictive factors in a large sample of Italian patients on chronic treatment. Eur Rev Med Pharmacol Sci. 2010;14(12):1045-1050.

18. Weschules DJ, Bain KT, Reifsnyder J, et al. Toward evidence-based prescribing at end of life: a comparative analysis of sustained-release morphine, oxycodone, and transdermal fentanyl, with pain, constipation, and caregiver interaction outcomes in hospice patients. Pain Med. 2006;7(4):320-329.

19. Abramowitz L, Béziaud N, Labreze L, et al. Prevalence and impact of constipation and bowel dysfunction induced by strong opioids: a cross-sectional survey of 520 patients with cancer pain: DYONISOS study. J Med Econ. 2013;16(12):1423-1433.
20. Reimer K, Hopp M, Zenz M, et al. Meeting the challenges of opioidinduced constipation in chronic pain management - a novel approach. Pharmacology. 2009;83(1):10-17.

21. Davis MP. The opioid bowel syndrome: a review of pathophysiology and treatment. J Opioid Manag. 2005;1(3):153-161.

22. Holzer P. Treatment of opioid-induced gut dysfunction. Expert Opin Investig Drugs. 2007;16(2):181-194.

23. Holzer P. Opioids and opioid receptors in the enteric nervous system: from a problem in opioid analgesia to a possible new prokinetic therapy in humans. Neurosci Lett. 2004;361(1-3):192-195.

24. Shook JE, Pelton JT, Hruby VJ, Burks TF. Peptide opioid antagonist separates peripheral and central opioid antitransit effects. J Pharmacol Exp Ther. 1987;243(2):492-500.

25. Sykes NP. Constipation and diarrhoea. In: Doyle D, Hanks G, Cherny N, Calman K, editors. Oxford Textbook of Palliative Medicine. 2nd ed. Oxford: Oxford University Press; 2004:483-496.

26. Basta S, Anderson DL. Mechanisms and management of constipation in the cancer patient. J Pharmaceut Care Pain Symptom Control. 1998; 6(3):21-40.

27. Potter J, Wagg A. Management of bowel problems in older people: an update. Clin Med. 2005;5(3):289-295.

28. Mumford SP. Can high fibre diets improve the bowel function in patients on radiotherapy ward. In: Twycross RG, Lack SA, editors. Control of Alimentary Symptoms in Far Advanced Cancer. Edinburgh: Churchill Livingstone; 1986:183.

29. Porecca F, Cowan A, Raffa RB, Tallarida RJ. Ketazocines and morphine: effects on gastrointestinal transit after central and peripheral administration. Life Sci. 1983;32(15):1785-1790

30. Parolado D, Sala M, Gori E. Effect of intracerebroventricular administration of morphine upon intestinal motility in rat and its antagonism with naloxone. Eur J Pharmacol. 1977;46(4):329-338.

31. Stewart JJ, Weisbrodt NW, Burks TF. Central and peripheral action of morphine on intestinal transit. J Pharmacol Exp Ther. 1978;205(3): 547-555.

32. Thörn SE, Wattwil M, Lindberg G, Säwe J. Systemic and central effects of morphine on gastrointestinal motility. Acta Anaesthesiol Scand. 1996; 40(2):177-186

33. Thomas J, Karver S, Cooney GA, et al. Methylnaltrexone for opioidinduced constipation in advanced illness. N Engl J Med. 2008;358(22): 2332-2343.

34. Slatkin N, Thomas J, Lipman AG, et al. Methylnaltrexone for treatment of opioid-induced constipation in advanced illness patients. $J$ Support Oncol. 2009;7(1):39-46.

35. Wood JD, Galligan JJ. Function of opioids in the enteric nervous system. Neurogastroenterol Motil. 2004;16(Suppl 2):17-28.

36. Rentz AM, Yu R, Müller-Lissner S, Leyendecker P. Validation of the Bowel Function Index to detect clinically meaningful changes in opioid-induced constipation. J Med Econ. 2009;12(4):371-383.

37. Ueberall MA, Müller-Lissner S, Bushmann-Kramm C, Bosse B. The Bowel Function Index for evaluating constipation in pain patients: definition of a reference range for a non-constipated population of pain patients. $J$ Int Med Res. 2011;39(1):41-50.

38. Rentz AM, van Hanswijck de Jonge P, Leyendecker P, Hopp M. Observational, nonintervention, multicenter study for validation of the Bowel Function Index for constipation in European countries. Curr Med Res Opin. 2011;27(1):35-44.

39. Abramowitz L, Béziaud N, Caussé C, Chuberre B, Allaert FA, Perrot S. Further validation of the psychometric properties of the Bowel Function Index for evaluating opioid-induced constipation (OIC). J Med Econ. 2013;16(12):1434-1441.

40. Slappendel R, Simpson K, Dubois D, Keininger DL. Validation of the PAC-SYM questionnaire for opioid-induced constipation in patients with chronic low back pain. Eur J Pain. 2006;10(3):209-217.

41. Marquis P, De La Loge C, Dubois D, McDermott A, Chassany O. Development and validation of the Patient Assessment of Constipation Quality of Life questionnaire. Scand J Gastroenterol. 2005;40(5): $540-551$. 
42. Lewis SJ, Heaton KW. Stool form scale a useful guide to intestinal transit time. Scand J Gastroenterol. 1997;32(9):920-924.

43. Olesen AE, Drewes AM. Validated tools for evaluating opioid-induced bowel dysfunction. Adv Ther. 2011;28(4):279-294.

44. Rauck RL. Treatment of opioid-induced constipation: focus on the peripheral $\mu$-opioid receptor antagonist methylnaltrexone. Drugs. 2013; 73(12):1297-1306.

45. Desta Z, Wu GM, Morocho AM, Flockhart DA. The gastroprokinetic and antiemetic drug metoclopramide is a substrate and inhibitor of cytochrome P450 2D6. Drug Metab Dispos. 2002;30(3): 336-343.

46. Glare P, Nikolova T, Tickoo R, Miller J, Bras M. An overview of antiemetic medications and the considerations for their use in palliative care. Eur J Palliat Care. 2012;19:162-167.

47. Twycross R, Wilcock A. Gastro-intestinal system. In: Twycross R, Wilcock A, editors. Palliative Care Formulary. 4th ed. Milton Keynes: Radcliffe Publishing; 2012:1-54.

48. Potet F, Bouyssou T, Escande D, Baró I. Gastrointestinal prokinetic drugs have different affinity for the human cardiac ether-à-gogo $\mathrm{K}(+)$ channel. J Pharmacol Exp Ther. 2001;299(3):1007-1012.

49. Chojnacki J. [Itopride in the treatment of kinetic disorders of gastrointestinal tract]. Przegl Gastroentorol. 2011;6:139-145. Polish.

50. Bouras EP, Camilleri M, Burton DD, Thomforde G, McKinzie S, Zinsmeister AR. Prucalopride accelerates gastrointestinal and colonic transit in patients with constipation without a rectal evacuation disorder. Gastroenterology. 2001;120(2):354-360.

51. Tack J, van Outryve M, Beyens G, Kerstens R, Vandeplassche L. Prucalopride (Resolor) in the treatment of severe chronic constipation in patients dissatisfied with laxatives. Gut. 2009;58(3):357-365.

52. Quigley EM. Prucalopride: safety, efficacy and potential applications. Therap Adv Gastroenterol. 2012;5(1):23-30.

53. Sloots CE, Rykx A, Cools M, Kerstens R, De Pauw M. Efficacy and safety of prucalopride in patients with chronic noncancer pain suffering from opioid-induced constipation. Dig Dis Sci. 2010;55(10): 2912-2921.

54. Thayalasekeran S, Ali H, Tsai HH. Novel therapies for constipation. World J Gastroenterol. 2013;19(45):8247-8251.

55. Cuppoletti J, Chakrabarti J, Tewari K, Malinowska DH. Methadone but not morphine inhibits lubiprostone-stimulated $\mathrm{Cl}$ - currents in T84 intestinal cells and recombinant human ClC-2, but not CFTR Cl- currents. Cell Biochem Biophys. 2013;66(1):53-63.

56. Müller-Lissner S. Pharmacokinetic and pharmacodynamic considerations for the current chronic constipation treatments. Exp Opin Drug Metab Toxicol. 2013;9(4):391-401.

57. Busby RW, Kessler MM, Bartolini WP, et al. Pharmacologic properties, metabolism, and disposition of linaclotide, a novel therapeutic peptide approved for the treatment of irritable bowel syndrome with constipation and chronic idiopathic constipation. J Pharmacol Exp Ther. 2013;344(1):196-206.

58. Larkin PJ, Sykes NP, Centeno C, et al; European Consensus Group on Constipation in Palliative Care. The management of constipation in palliative care: clinical practice recommendations. Palliat Med. 2008; 22(7):796-807.

59. Holzer P, Ahmedzai SH, Niederle N, et al. Opioid-induced bowel dysfunction in cancer-related pain: causes, consequences, and a novel approach for its management. J Opioid Manag. 2009;5(3): $145-195$.

60. Leppert $\mathrm{W}$. The impact of opioid analgesics on the gastrointestinal tract function and the current management possibilities. Contemp Onkol (Pozn). 2012;16(2):125-131.

61. Mercadante S, Casuccio A, Fulfaro F, et al. Switching from morphine to methadone to improve analgesia and tolerability in cancer patients: a prospective study. J Clin Oncol. 2001;19(11):2898-2904.

62. Ahmedzai S, Brooks D; the TTS-Fentanyl Comparative Trial Group. Transdermal fentanyl versus sustained-release oral morphine in cancer pain: preference, efficacy, and quality of life. J Pain Symptom Manage. 1997;13(5):254-261.
63. Wirz S, Witmmann M, Schenk M, et al. Gastrointestinal symptoms under opioid therapy: a prospective comparison of oral sustained-release hydromorphone, transdermal fentanyl, and transdermal buprenorphine. Eur J Pain. 2009;13(7):737-743.

64. Bader S, Dürk T, Becker G. Methylnaltrexone for the treatment of opioid-induced constipation. Expert Rev Gestroenterol Hepatol. 2013; 7(1):13-26.

65. Leppert W. Role of oxycodone and oxycodone/naloxone in cancer pain management. Pharmacol Rep. 2010;62(4):578-591.

66. Meissner W, Schmidt U, Hartmann N, Kath R, Reinhart K. Oral naloxone reverses opioid-associated constipation. Pain. 2000;84(1):105-109.

67. Meissner W, Leyendecker P, Mueller-Lissner S, et al. A randomised controlled trial with prolonged-release oral oxycodone and naloxone to prevent and reverse opioid-induced constipation. Eur J Pain. 2009; 13(1):56-64.

68. Nadstawek J, Leyendecker P, Hopp M, et al. Patient assessment of a novel therapeutic approach for the treatment of severe, chronic pain. Int J Clin Pract. 2008;62(8):1159-1167.

69. Targinact $5 \mathrm{mg} / 2.5 \mathrm{mg}, 10 \mathrm{mg} / 5 \mathrm{mg}, 20 \mathrm{mg} / 10 \mathrm{mg}$ and $40 \mathrm{mg} / 20 \mathrm{mg}$ prolonged-release tablets. Surrey, England: The electronic Medicines Compendium (eMC). Datapharm Communications Limited [updated November 23, 2012]. Available from: https://www.medicines.org.uk/ emc/medicine/22908access\%2023\%20November\%202014. Accessed November 23, 2014.

70. Riley J, Eisenberg E, Müller-Schwefe G, Drewers AM, Arendt-Nielsen L. Oxycodone: a review of its use in the management of pain. Curr Med Res Opin. 2008;24(1):175-192.

71. Liu M, Wittbrodt E. Low-dose oral naloxone reverses opioidinduced constipation and analgesia. J Pain Symptom Manage. 2002; 23(1):48-53.

72. Targin ${ }^{\circledR}$ (oxycodone hydrochloride and naloxone hydrochloride dihydrate) [package insert]. Cambridge, UK: Mundipharma International; 2011. Polish.

73. Smith K, Hopp M, Mundin G, et al. Naloxone as a part of a prolonged release oxycodone/naloxone combination reduces oxycodone-induced slowing of gastrointestinal transit in healthy volunteers. Expert Opin Investig Drugs. 2011;20(4):427-439.

74. Samer CF, Daali Y, Wagner M, et al. Genetic polymorphism and drug interactions modulating CYP2D6 and CYP3A activities have a major effect on oxycodone analgesic efficacy and safety. Br J Pharmacol. 2010;160(4):919-930.

75. Reimer K, Hopp M, Zenz M, et al. Meeting the challenges of opioidinduced constipation in chronic pain management - a novel approach. Pharmacology. 2009;83(1):10-17.

76. Smith K, Hopp M, Mundin G, et al. Single- and multiple-dose pharmacokinetic evaluation of oxycodone and naloxone in an opioid agonist/ antagonist prolonged-release combination in healthy adult volunteers. Clin Ther. 2008;30(11):2051-2068.

77. Leppert W. Oxycodone/naloxone in the management of patients with pain and opioid-induced bowel dysfunction. Curr Drug Targets. 2014;15(1):124-135.

78. Webster LR, Slevin KA, Narayana A, Earl CQ, Yang R. Fentanyl buccal tablet compared with immediate-release oxycodone for the management of breakthrough pain in opioid-tolerant patients with chronic cancer and noncancer pain: a randomized, double-blind, crossover study followed by a 12 -week open-label phase to evaluate patient outcomes. Pain Med. 2013;14(9):1332-1345.

79. Vondrackova D, Leyendecker P, Meissner W, et al. Analgesic efficacy and safety of oxycodone in combination with naloxone as prolonged release tablets in patients with moderate to severe chronic pain. J Pain. 2008;9(12):1144-1154.

80. Simpson K, Leyendecker P, Hopp M, et al. Fixed-ratio combination oxycodone/naloxone compared with oxycodone alone for the relief of opioid-induced constipation in moderate-to-severe noncancer pain. Curr Med Res Opin. 2008;24(12):3503-3512.

81. Smith K, Hopp M, Mundin G, et al. Low absolute bioavailability of oral naloxone in healthy subjects. Int J Clin Pharmacol Ther. 2012; 50(5):360-367. 
82. Schang JC, Devroede G. Beneficial effects of naloxone in a patient with intestinal pseudoobstruction. Am J Gastroenterol. 1985;80(6): 407-411.

83. Löwenstein O, Leyendecker P, Hopp M, et al. Combined prolongedrelease oxycodone and naloxone improves bowel function in patients receiving opioids for moderate-to-severe non-malignant chronic pain: a randomized controlled trial. Expert Opin Pharmacother. 2009;10(4): 531-543.

84. Sandner-Kiesling A, Leyendecker P, Hopp M, et al. Long-term efficacy and safety of combined prolonged-release oxycodone and naloxone in the management of non-cancer chronic pain. Int J Clin Pract. 2010; 64(6):763-774.

85. Löwenstein O, Leyendecker P, Lux EA, et al. Efficacy and safety of combined prolonged-release oxycodone and naloxone in the management of moderate/severe chronic non-malignant pain: results of a prospectively designed pooled analysis of two randomised, double-blind clinical trials. BMC Clin Pharmacol. 2010;10:12

86. Ahmedzai SH, Leppert W, Janecki M et al. Long-term safety and efficacy of oxycodone/naloxone prolonged-release tablets in patients with moderate-to-severe chronic cancer pain. Support Care Cancer. Epub 2014 Sep 14.

87. Blagden M, Hafer J, Duerr H, Hopp M, Bosse B. Long-term evaluation of combined prolonged-release oxycodone and naloxone in patients with moderate-to-severe chronic pain: pooled analysis of extension phases of two Phase III trials. Neurogastroenterol Motil. 2014;26(12):1792-1801.

88. Mercadante S, Ferrera P, Adile C. High doses of oxycodone-naloxone combination may provide poor analgesia. Support Care Cancer. 2011; 19(9):1471-1472.

89. Kang JH, Lee GW, Shin SH, Bruera E. Opioid withdrawal syndrome after treatment with low-dose extended-release oxycodone and naloxone in a gastric cancer patient with portal vein thrombosis. J Pain Symptom Manage. 2013;46(2):e15-e17.

90. Cloutier C, Taliano J, O’Mahony W, et al. Controlled-release oxycodone and naloxone in the treatment of chronic low back pain: a placebocontrolled, randomized study. Pain Res Manag. 2013;18(2):75-82.

91. Hermanns K, Junker U, Nolte T. Prolonged-release oxycodone/naloxone in the treatment of neuropathic pain - results from a large observational study. Expert Opin Pharmacother. 2012;13(3):299-311.

92. Gatti A, Casali M, Lazzari M, et al. Prolonged-release oxycodone/ naloxone in nonmalignant pain: single-center study in patients with constipation. Adv Ther. 2013;30(1):41-59.

93. Dunlop W, Uhl R, Khan I, Taylor A, Barton G. Quality of life benefits and cost impact of prolonged release oxycodone/naloxone versus prolonged release oxycodone in patients with moderate-to-severe non-malignant pain and opioid-induced constipation: a UK cost-utility analysis. J Med Econ. 2012;15(3):564-575.

94. Coluzzi F, Ruggeri M. Clinical and economic evaluation of tapentadol extended release and oxycodone/naloxone extended release in comparison with controlled release oxycodone in musculoskeletal pain. $\mathrm{Curr}$ Med Res Opin. 2014;30(6):1139-1151.

95. Lazzari M, Sabato AF, Caldarulo C, et al. Effectiveness and tolerability of low-dose oral oxycodone/naloxone added to anticonvulsant therapy for noncancer neuropathic pain: an observational analysis. Curr Med Res Opin. 2014;30(4):555-564.

96. Ahmedzai SH, Nauck F, Bar-Sela G, Bosse B, Leyendecker P, Hopp M. A randomized, double-blind, active-controlled, double-dummy, parallel-group study to determine the safety and efficacy of oxycodone/ naloxone prolonged-release tablets in patients with moderate/severe, chronic cancer pain. Palliat Med. 2012;26(1):50-60.

97. Clemens KE, Quednau I, Klaschik E. Bowel function during pain therapy with oxycodone/naloxone prolonged-release tablets in patients with advanced cancer. Int J Clin Pract. 2011;65(4):472-478.

98. Schutter U, Grunert S, Meyer C, Schmidt T, Nolte T. Innovative pain therapy with a fixed combination of prolonged-release oxycodone/ naloxone: a large observational study under conditions of daily practice. Curr Med Res Opin. 2010;26(6):1377-1387.
99. Cuomo A, Russo G, Esposito G, Forte CA, Connola M, Marcassa C. Efficacy and gastrointestinal tolerability of oral oxycodone/naloxone combination for chronic pain in outpatients with cancer: an observational study. Am J Hosp Palliat Care. Epub 2013 Nov 17.

100. Kuusniemi K, Zöllner J, Sjövall S, et al. Prolonged-release oxycodone/ naloxone in postoperative pain management: from a randomized clinical trial to usual clinical practice. J Int Med Res. 2012;40(5): 1775-1793.

101. Comelon M, Wisloeff-Aase K, Raeder J, et al. A comparison of oxycodone prolonged-release vs. oxycodone + naloxone prolongedrelease after laparoscopic hysterectomy. Acta Anaesthesiol Scand. 2013;57(4):509-517.

102. Shaiova L, Rim F, Friedman D, Jahdi M. A review of methylnaltrexone, a peripheral opioid receptor antagonist, and its role in opioidinduced constipation. Palliat Support Care. 2007;5(2):161-166.

103. Yuan CS, Israel RJ. Methylnaltrexone, a novel peripheral opioid receptor antagonist for the treatment of opioid side effects. Expert Opin Investig Drugs. 2006;15(5):541-552.

104. Sobczak M, Salaga M, Storr MA, Fichna J. Physiology, signaling, and pharmacology of opioid receptors and their ligands in the gastrointestinal tract: current concepts and future perspectives. J Gastroenterol. 2014;49(1):24-45.

105. Yuan CS, Foss JF, Osinski J, Toledano A, Roizen MF, Moss J. The safety and efficacy of oral methylnaltrexone in preventing morphineinduced delay in oral-cecal transit time. Clin Pharmacol Ther. 1997; 61(4):467-475.

106. Yuan CS, Foss JF, O'Connor M, et al. Effects of enteric-coated methylnaltrexone in preventing opioid-induced delay in oral-cecal transit time. Clin Pharmacol Ther. 2000;67(4):398-404.

107. Yuan CS. Clinical status of methylnaltrexone, a new agent to prevent and manage opioid-induced side effects. J Support Oncol. 2004;2(2): 119-122.

108. Abarca FM, Saclarides TJ, Brand MI. A review of the treatment of opioid-induced constipation with methylnaltrexone bromide. Clin Med Insight: Ther. 2010;2:53-60.

109. Kotake AN, Kuwahara SK, Burton E, McCoy CE, Goldberg LI. Variations in demethylation of N-methylnaltrexone in mice, rats, dogs, and humans. Xenobiotica. 1989;19(11):1247-1254.

110. Chandrasekaran A, Tong Z, Li H, et al. Metabolism of intravenous methylnaltrexone in mice, rats, dogs, and humans. Drug Metab Dispos. 2010;38(4):606-616.

111. McNicol E, Boyce DB, Schumann R, Carr D. Efficacy and safety of mu-opioid antagonists in the treatment of opioid-induced bowel dysfunction: systematic review and meta-analysis of randomized controlled trials. Pain Med. 2008;9(6):634-659.

112. McNicol ED, Boyce D, Schumann R, Carr DB. Mu-opioid antagonists for opioid-induced bowel dysfunction. Cochrane Database Syst Rev. 2008;16(2):CD006332.

113. Candy B, Jones L, Goodman ML, Drake R, Tookman A. Laxatives or methylnaltrexone for the management of constipation in palliative care patients. Cochrane Database Syst Rev. 2011;19(1):CD003448.

114. Ford AC, Brenner DM, Schoenfeld PS. Efficacy of pharmacological therapies for the treatment of opioid-induced constipation: systematic review and meta-analysis. Am J Gastroenterol. 2013;108(10): 1566-1572.

115. Moerman I, Franck P, Camu F. Evaluation of methylnaltrexone for the reduction of postoperative vomiting and nausea incidences. Acta Anaesthsiol Belg. 1995;46(3-4):127-132.

116. Portenoy RK, Thomas J, Moehl Boatwright ML, et al. Subcutaneous methylnaltrexone for the treatment of opioid-induced constipation in patients with advanced illness: a double-blind, randomized, parallel group, dose-ranging study. J Pain Symptom Manage. 2008;35(5): $458-468$

117. Chamberlain BH, Cross K, Winston JL, et al. Methylnaltrexone treatment of opioid-induced constipation in patients with advanced illness. J Pain Symptom Manage. 2009;38(5):683-690.

118. Clemens KE, Klaschik E. Managing opioid-induced constipation in advanced illness: focus on methylnaltrexone bromide. Ther Clin Risk Manag. 2010;6:77-82. 
119. Deibert P, Xander C, Blum HE, Becker G. Methylnaltrexone: the evidence for its use in the management of opioid-induced constipation. Core Evid. 2010;4:247-258.

120. RELISTOR (methylnaltrexone bromide) Subcutaneous Injection [prescribing information]. Tarrytown, NY: Progenics Pharmaceuticals, Inc. [updated September 2014]. Available from: http://cdn.salix.com/ shared/pi/relistor-pi.pdf. Accessed November 23, 2014.

121. Lipman AG, Karver S, Kooney GA, Stambler N, Israel RJ. Methylnaltrexone for opioid-induced constipation in patients with advanced illness: a 3-month open-label treatment extension study. J Pain Palliat Care Pharmacother. 2011;25(2):136-145.

122. Slatkin NE, Lynn R, Su C, Wang W, Israel RJ. Characterization of abdominal pain during methylnaltrexone treatment of opioid-induced constipation in advanced illness: a post hoc analysis of two clinical trials. J Pain Symptom Manage. 2011;42(5):754-760.

123. Stettler A, Zulian GB. Unexpected side effect of methylnaltrexone. J Palliat Med. 2013;16(10):1168.

124. Mackey AC, Green L, Greene P, Avigan M. Methylnaltrexone and gastrointestinal perforation. J Pain Symptom Manage. 2010; 40(1):e1-e3.

125. Watkins J, Eckmann KR, Mace ML, Rogers J, Langley G, Smith W. Utilization of methylnaltrexone (Relistor) for opioid-induced constipation in an oncology hospital. P T. 2011;36(1):33-36.

126. Centeno C, Carranza O, Zuriarrain Y, et al. A prospective study of methylnaltrexone for opioid-induced constipation in advanced illness: should we use it or not? J Pain Symptom Manage. 2013;46(5): e1-e3.

127. Michna E, Blonsky ER, Schulman S, et al. Subcutaneous methylnaltrexone for treatment of opioid-induced constipation in patients with chronic, non-malignant pain: a randomized controlled study. J Pain. 2011;12(5):554-562.

128. Iyer SS, Randazzo BP, Tzanis EL, et al. Effect of subcutaneous methylnaltrexone on patient-reported constipation symptoms. Value Health. 2011;14(1):177-183.

129. Michna E, Weil AJ, Duerden M, et al. Efficacy of subcutaneous methylnaltrexone in the treatment of opioid-induced constipation: a responder post hoc analysis. Pain Med. 2011;12(8):1223-1230.

130. Yuan CS, Foss JF, O'Connor M, et al. Methylnaltrexone for reversal of constipation due to chronic methadone use: a randomized controlled trial. JAMA. 2000;283(3):367-372.

131. Rodrigues A, Wong C, Mattiussi A, Alexander S, Lau E, Dupuis LL. Methylnaltrexone for opioid-induced constipation in pediatric oncology patients. Pediatr Blood Cancer. 2013;60(10):1667-1670.

132. Yu CS, Chun HK, Stambler N, et al. Safety and efficacy of methylnaltrexone in shortening the duration of postoperative ileus following segmental colectomy: results of two randomized, placebo-controlled phase 3 trials. Dis Col Rect. 2011;54(5):570-578.
133. Diego L, Atayee R, Helmons P, Hsiao G, von Gunten CF. Novel opioid antagonists for opioid-induced bowel dysfunction. Expert Opin Investig Drugs. 2011;20(8):1047-1056.

134. Webster L, Dhar S, Eldon M, Masuoka L, Lappalainen J, Sostek M. A phase 2, double-blind, randomized, placebo-controlled, doseescalation study to evaluate the efficacy, safety, and tolerability of naloxegol in patients with opioid-induced constipation. Pain. 2013; 154(9):1542-1550.

135. Chey WD, Webster L, Sostek M, Lappalainen J, Barker PN, Tack J. Naloxegol for opioid-induced constipation in patients with noncancer pain. N Engl J Med. 2014;370(25):2387-2396.

136. MOVANTIK is now FDA approved [webpage on the Internet]. Wilmington, DE: AstraZeneca; 2014 [updated September 2014]. Available from: https://www.movantikhcp.com/. Accessed November 23, 2014.

137. Paulson DM, Kennedy DT, Donovick RA, et al. Alvimopan: an oral, peripherally acting, mu-opioid receptor antagonist for the treatment of opioid-induced bowel dysfunction - a 21-day treatment-randomized trial. J Pain. 2005;6(3):184-192.

138. Büchler MW, Seiler CM, Monson JR, et al. Clinical trial: alvimopan for the management of post-operative ileus after abdominal surgery: results of an international randomized, double-blind, multicentre, placebo-controlled clinical study. Aliment Pharmacol Ther. 2008; 28(3):312-325.

139. Ludwig K, Enker WE, Delaney CP, et al. Gastrointestinal tract recovery in patients undergoing bowel resection: results of a randomized trial of alvimopan and placebo with a standardized accelerated postoperative care pathway. Arch Surg. 2008;143(11):1098-1105.

140. Entereg (alvimopan) capsules. Detailed View: Safety Labeling Changes Approved By FDA Center for Drug Evaluation and Research (CDER). Silver Spring, MD: US Food and Drug Administration [updated October 2013]. Available from: http://www.fda.gov/safety/ medwatch/safetyinformation/ucm194328.htm. Accessed July 22, 2014

141. Vickery R, Webster, L, Li Y-P, et al. No evidence of analgesic interference or CNS opioid withdrawal for TD-1211 in a Phase 2b study in Opioid-Induced Constipation (OIC). Poster presented at: The American Pain Society 32nd Annual Scientific Meeting; May 8-11; 2013; New Orleans, LA.

142. Mori T, Shibasaki Y, Matsumoto K, et al. Mechanisms that underlie $\mu$-opioid receptor agonist-induced constipation: differential involvement of $\mu$-opioid receptor sites and responsible regions. J Pharmcol Exp Ther. 2013;347(1):91-99.
Drug Design, Development and Therapy

\section{Publish your work in this journal}

Drug Design, Development and Therapy is an international, peerreviewed open-access journal that spans the spectrum of drug design and development through to clinical applications. Clinical outcomes, patient safety, and programs for the development and effective, safe, and sustained use of medicines are a feature of the journal, which

\section{Dovepress}

has also been accepted for indexing on PubMed Central. The manuscript management system is completely online and includes a very quick and fair peer-review system, which is all easy to use. Visit http://www.dovepress.com/testimonials.php to read real quotes from published authors. 